\title{
AS DIMENSÕES FORMATIVO-MUSICAIS NA ONG ILHA DE MÚSICA: UMA PERSPECTIVA SOBRE O ENSINO DE MÚSICA DE UM PROJETO SOCIAL
}

\author{
The formative-musical dimensions at the \\ NGO Ilha de Música: a perspective on the \\ teaching of music from a social project
}

\author{
Las dimensiones formativo-musicales en la \\ ONG Ilha de Música: una perspectiva sobre \\ la enseñanza de la música desde un proyecto \\ social
}

\author{
JosÉ DA SILVA FonTes JUNIOR \\ Instituto de Música Waldemar de Almeida \\ zefontesjr@hotmail.com \\ VAlÉria Lazaro de CARVAlHo \\ Universidade Federal do Rio Grande do Norte \\ vcarvalhodeart@msn.com
}

\begin{abstract}
Resumo: Este artigo é um recorte de uma pesquisa de mestrado que trata sobre as abordagens de educação musical adotadas pela ONG Ilha de Música, localizada no bairro da Redinha, na comunidade da África, Zona Norte do município de Natal (RN). O texto apresenta discussões sobre o ensino de música em ONGs, formação docente para esse contexto, a diversidade cultural no âmbito dos projetos sociais, o processo metodológico no qual a pesquisa se desenvolve e uma contextualização da ONG Ilha de Música. Para o desenvolvimento da pesquisa foi utilizada a metodologia de abordagem qualitativa, valendo-se da pesquisa documental e da técnica do estudo de caso. Os dados foram levantados mediante entrevistas realizadas com os participantes envolvidos no projeto; observações de campo (participativas e não participativas); utilização de um caderno de campo, bem como gravações de áudios e vídeos. Nos resultados, evidencia-se o uso de uma abordagem de ensino pautada por práticas que valorizam a intuição e a criatividade, sem abrir mão do desenvolvimento técnico e do estudo teórico musical.
\end{abstract}

Palavras-chave: Educação musical. Intervenção social. Diversidade cultural.

Abstract: This article is an excerpt from a master's research that deals with the musical education approaches adopted by the NGO Ilha de Música located in the Neighborhood of Redinha, in the community of Africa, North Zone of the municipality of Natal - RN. The text presents discussions on the teaching of music in NGOs, teacher training for this context, cultural diversity within the scope of Social Projects, the methodological process in which research develops and a contextualization of the NGO Ilha de Música. For the development of the research, the methodology of qualitative approach was used, using the documentary research and the technique of the Case Study. The data were collected through interviews with the participants involved in the project; field observations (participatory and non-participatory); use of a field notebook, as well as audio and video recordings. The results show the use of a teaching approach based on practices that value intuition and creativity, without giving up technical development and theoretical musical study.

Keywords: Music education. Social intervention. Cultural diversity.

Resumen: Este artículo es un extracto de una investigación de maestría que aborda los enfoques de educación musical adoptados por la ONG Ilha de Música ubicada en el barrio de Redinha, en la comunidad de África, Zona Norte de Natal - RN. El texto presenta discusiones sobre la enseñanza de la música en las ONG, la formación de docentes para este contexto, la diversidad cultural en el ámbito de los Proyectos Sociales, el proceso metodológico en el que se desarrolla la investigación y una contextualización de la ONG Ilha de Música. Para el desarrollo de la investigación se utilizó la metodología de enfoque cualitativo, haciendo uso de la investigación documental y la técnica del Estudio de Caso. Los datos fueron recolectados a través de entrevistas con los participantes involucrados en el proyecto; observaciones de campo (participativas y no participativas); uso de un cuaderno de campo, así como grabaciones de audio y video. Los resultados muestran el uso de un enfoque de enseñanza basado en prácticas que valoran la intuición y la creatividad, sin renunciar al desarrollo técnico y al estudio musical teórico.

Palabras clave: Educación musical. Intervención social. Diversidad cultural. 


\section{INTRODUÇÃO}

O ensino de música tem se estruturado em dimensões cada vez mais amplas e diversificadas. Assim como as culturas se encontram em constantes transformações, o uso da música e as formas de sua transmissão tendem a acompanhar as necessidades emergentes de cada contexto social. Nesse sentido, o terceiro setor mostra-se como uma dimensão da sociedade, na qual desde a década de 1990 em nosso país - têm se expandido os projetos sociais e as organizações não governamentais (ONGs). Esses espaços visam atender às populações de baixa renda, sobretudo crianças e adolescentes que se encontram em situação de vulnerabilidade social. Por esse contexto, o uso da música como meio de socialização e ação educativa vem sendo adotado, inspirando reflexões, debates e pesquisas, proporcionando aproximações epistemológicas entre a área da música, suas subáreas e outras áreas do conhecimento, como a educação, a sociologia, a psicologia e a antropologia.

Esse estudo é fundamentado por referenciais teóricos de Geertz (1973), Blacking (2007), Bauman (1997) e Freire (1997). Por se tratar de um recorte de uma pesquisa de mestrado, para este artigo foram utilizados apenas os três primeiro autores citados.

A pesquisa em questão foi desenvolvida no decorrer dos anos de 2017 e 2018, durante um processo de titulação de mestrado do Programa de Pós-Graduação em Música da Universidade Federal do Rio Grande do Norte (UFRN), e teve como foco o trabalho educativo-musical desenvolvido pela organização não governamental Ilha de Música. Trata-se de uma instituição que por 12 anos vem atuando com ensino de música para crianças e adolescentes, atendendo à população do bairro da Redinha, mais precisamente a comunidade da África, situada na Zona Norte do municipio de Natal (RN). Sendo uma investigação que buscou compreender a educação musical adotada por um projeto social, o objetivo geral da pesquisa foi identificar e compreender as dimensões formativo-musicais que norteavam as ações educativas nesse espaço.

Este texto está composto por abordagens que tratam do ensino de música em ONGs (incluindo aspectos sobre a formação docente), a diversidade cultural no âmbito dos projetos sociais, bem como discussões que explicam e justificam o processo metodológico desenvolvido. Apresenta o projeto social Ilha de Música, suas atividades, um pouco sobre o seu histórico, a análise dos resultados da pesquisa e as considerações finais.

Para identificar e compreender as dimensões formativas musicais que norteiam as ações educativas da ONG Ilha de Música, foi imprescindível detectar os fenômenos que se relacionam diretamente com sua ação educativa, e assim procurar entendê-los em sua totalidade. Por esse viés, o uso da modalidade da pesquisa qualitativa do estudo de caso, pela sua possibilidade marcante de aprofundamento (Laville; Dione, 1999), mostrou-se como o caminho a ser trilhado.

Além das entrevistas semiestruturadas realizadas com sete profissionais atuantes no projeto, foram observadas aulas, ensaios, bastidores de apresentações, apresentações em recitais internos e apresentações externas. Sendo 
assim, com os alicerces de toda uma teia de relações humanas que essas vivências proporcionaram, foram construidos os dados essenciais que permitiram chegar às dimensões formativas musicais na ONG Ilha de Música.

Com a análise dos resultados, ficou identificado que a educação musical desenvolvida pela Ilha de Música apresenta repercussões significativas em relação à formação musical e humana em seus alunos. Sobre suas dimensões formativas, os resultados revelam características pedagógicas em diferentes evidências. As particularidades inerentes às dimensões formativas que mais se destacaram estão relacionadas com a ética, a socialização, a diversidade, a oralidade nas transmissões musicais, o significado das práticas musicais e o compromisso com o desenvolvimento da autonomia nos alunos.

\section{O ENSINO DE MÚSICA EM ONGS: CONCEPÇÕES SOBRE O TEMA E FORMAÇÃO DOCENTE}

A discussão sobre o ensino de música em ONGs tem se desenvolvido em investigações científicas nas quais se evidenciam diversos exemplos de projetos atuantes. Essa temática tem favorecido relações interdisciplinares entre a área da educação musical e outras áreas do conhecimento, por exemplo, a educação, a psicologia, a sociologia e a antropologia. De acordo com essa perspectiva, Souza (2014, p. 11) observa que em cada campo de conhecimento surgem abordagens com características semelhantes, mas com "olhares diferenciados dependendo de seus objetos de pesquisas".

Kleber (2006) apresenta uma pesquisa que aborda a prática da educação musical em duas ONGs. Trata-se de um debate sobre a amplitude do "saber pedagógico" como elemento que no cotidiano estabelece novas formas de conhecimento musical, de apropriação e transmissão. Kleber $(2011,2014)$ enfoca a dinâmica da rede de sociabilidade musical nos projetos sociais e suas implicações no processo pedagógico musical, observando os sujeitos em sua individualidade e suas inter-relações coletivas. A autora destaca que nas ONGs em que realizou suas investigações, o significado do termo pedagógico não está restrito apenas aos processos de ensino e aprendizagem, e, sim, refere-se a um campo pluridimensional que interliga inúmeras dimensões. Nesse sentido, seus pressupostos teóricos estão amparados por uma visão que compreende as práticas musicais "enquanto uma experiência humana vivida concretamente em uma multiplicidade de contextos conectados" (Kleber, 2014, p. 35).

Também Kater (2004), educador musical, tratando da formação profissional docente, expõe algumas considerações sobre o mercado de trabalho na contemporaneidade. Argumenta que é em "decorrência da ampliação de perspectivas que as profissões evoluem" e assim inauguram novas conjunturas de trabalho expandindo suas condições de contribuição social (Kater, 2004 , p. 44). O autor observa a necessidade de novos perfis para o educador musical, que atendam às demandas das transformações emergentes na sociedade, exemplificando o ensino de música adotado em ONGs, como novas perspectivas para a formação humana ofertada pela educação musical. No 
que se refere ao papel formador que a educação musical pode atingir, o autor vem afirmar que:

Quando falamos neste sentido do papel formador do educador musical, seu esforço sistemático em dedicar-se ao crescimento musical e humano integrado (seu e de seus alunos), expressamos algo mais. Evocamos também uma concepção filosófica, uma postura política e alguma coragem, que dêem convicção à crença de que tudo o que é vivo tem movimento e o que se move possui direção e comporta transformação. As pessoas, a sociedade, o mundo são transformáveis, e direções para seu movimento podem ser criadas, inibidas ou reforçadas (Kater, 2004, p. 45).

Sua fala reforça a ideia do poder de transformação que a educação musical possui, como uma espécie de caráter vocacional capaz de contribuir com a criação de uma sociedade mais humana e menos desigual. Nesses argumentos o autor expõe as responsabilidades politicas do educador musical perante a sua função social.

Retornando a Souza (2014), a autora destaca o conceito do termo social relacionando-o diretamente à inclusão. Essa relação direta torna-se então uma das evidências básicas das ações sociais coletivas. Outro ponto relevante na abordagem de Souza (2014) - e esse em especial convergindo pontualmente com o objetivo principal desta investigação - ressalta a importância de uma análise e discussão político-pedagógica dos projetos sociais.

Nos projetos sociais, o educador deverá pensar nas condições de cada participante, em suas necessidades e peculiaridades. Sendo assim, a cada criança ou adolescente que sofreu algum tipo de trauma em sua socialização primária a educação musical poderá fornecer uma socialização secundária, e nesse caso estará contribuindo para uma "reconstituição do tecido social" (Souza, 2014, p. 21).

A concepção sobre a postura adequada de um educador atuante em projetos sociais apresentada por Souza (2014) reforça a ideia do ensino de música direcionado para as reais necessidades do aluno. Uma prática pedagógico-musical que tem como foco um ensino comprometido em preencher lacunas, em reorganizar e fortalecer estruturas psicológicas, uma ação educacional em que a socialização irá assumir um caráter humanitário, empenhado em suprir carências inerentes à formação dos individuos.

Oliveira (2003), em um estudo sobre a atuação profissional do educador musical no terceiro setor, foca suas discussões mais especificamente nas demandas de mercado do trabalho das ONGs. Para esse mercado de trabalho, o integrante da equipe necessita compreender a estrutura de funcionamento de sua instituição. É preciso conhecer o que está por trás do projeto e quais os reais interesses que o mobilizam. Ter consciência das "estruturas de funcionamento e dos seus recursos financeiros, humanos e materiais" (Oliveira, 2003 , p. 96). Sobretudo ao profissional que irá trabalhar em ONGs que utilizam a música como elemento de base, Oliveira (2003, p. 96) elenca algumas 
capacidades primordiais que deverão ser adquiridas em sua formação de educador musical, habilidades como: dominio técnico de um ou mais instrumentos musicais e canto; "capacidade criativa e expressiva"; "nivel de apreciação crítica do repertório musical"; consciência de suas próprias competências e saberes, modéstia, mas em equilíbrio com a autoconfiança e alegria pelo que consegue realizar; "capacidade de trabalho interdisciplinar". Entre outros requisitos, para esse profissional ter uma boa atuação em ONGs, ser detentor de uma "inteligência lógico-pedagógica" lhe possibilitará atuar levando em consideração o contexto inerente à população que frequenta um determinado projeto social (Oliveira, 2003, p. 96).

A fala da autora dimensiona a amplitude que envolve o trabalho de um educador musical em projetos sociais. As exigências de habilidades descritas por Oliveira (2003) nos permitem trazer para o debate algumas problemáticas que envolvem a formação profissional do educador musical. No que diz respeito às habilidades técnicas inerentes à execução de instrumentos musicais e canto - não com intuito de apontar alternativas e sim de provocar reflexões - lançamos dois questionamentos: os domínios dessas habilidades são devidamente trabalhados nos cursos de licenciatura em música? Os cursos de bacharelados em música, que são mais comprometidos com as questões técnicas musicais, trabalham devidamente os aspectos humanísticos na formação profissional? Para responder a essas perguntas, se necessitaria um aprofundamento na questão curricular dos cursos de licenciatura e bacharelado em música. Não tendo essa intenção, apenas observamos que a atuação em ONGs exige do educador musical um desdobramento de suas capacidades e constante reflexão sobre suas ações humanísticas.

No que diz respeito à preparação humanística, Nascimento (2014, p. 60) aborda a inquietação dos pensadores humanistas da contemporaneidade, referindo-se ao distanciamento existente entre os sistemas de ensino e as sociedades:

A formação profissionalizante do sistema de ensino superior nem sempre tem em conta a preparação humanística dos profissionais para que atuem tendo como foco a promoção da vida. O mais comum tem sido a preocupação com a sua inserção no mercado de trabalho, com muita competência técnica e pouco sentimento humanístico.

Diante desse quadro, é possível observar que o trabalho realizado em ONGs, por meio de seus exemplos e de suas características descritas pelos autores citados, pode muito ampliar as discussões de caráter formativo-musical e, consequentemente, contribuir com a educação em âmbito geral.

Nos aprofundando um pouco mais sobre a temática da formação do educador musical, é possivel destacar que a atuação profissional dos egressos do curso de licenciatura em música quase sempre nos remete à educação básica regular. Alguns autores, a exemplo de Bellochio (2016); Penna, Barros e Melo (2012); Del Ben (2003); Almeida (2010); Araujo (2012); Moraes (2006), advertem sobre a existência dos múltiplos espaços que abrangem a área da música 
e de sua transmissão, evidenciando que as constantes transformações sociais indicam novos contextos de atuação profissional, novos rumos para formação em música e, assim sendo, novos desafios. Integrando essa pluralidade de ambientes possiveis para atuação do educador musical estão as ONGs e os projetos sociais.

Esses autores dialogam com os fenômenos observados nas dimensões formativo-musicais da ONG Ilha de Música. Considerando essas abordagens, consciente da multiplicidade de estudos que envolvem trabalhos sociais aqui não citados, e buscando ampliar as discussões sobre o ensino de música em ONGs, nasce a necessidade de trazer para o foco de debate desta pesquisa a diversidade cultural na esfera dos projetos sociais.

\section{A DIVERSIDADE CULTURAL NO ÂMBITO DOS PROJETOS SOCIAIS}

Durante o processo da pesquisa sobre a Ilha de Música, a revisão bibliográfica e algumas experiências vivenciadas em campo permitiram identificar que o tema da diversidade cultural tem forte impacto, sobretudo nas discussões em torno dos aspectos músico-pedagógicos em projetos sociais que fazem uso do fenômeno musical como um meio de intervenção social. A própria Ilha de Música - tomando como base a observação empírica - mostra-se como um espaço educativo no qual são diversas as práticas musicais e os gêneros musicais abordados e contextualizados, tanto em aulas de musicalização infantil como nas aulas de instrumentos. Os projetos sociais estão reconhecidos como espaços que favorecem o desenvolvimento de concepções pedagógicas musicais contextualizadas e significativas, tornando-se, então, um desafio epistemológico para a área de música e suas subáreas.

Atualmente a educação musical se estabelece como "um campo diversificado de estudos e práticas de formação em música", abrangendo múltiplos espaços, e assim tornando-se uma área compreendida como "uma complexa rede de interações" (Queiroz, 2013, p. 95); desse modo, tornou-se relevante para esta pesquisa compreender os processos educacionais sob a ótica da diversidade cultural.

Para dar início a essa abordagem, será dado destaque ao tema da diversidade cultural em projetos sociais, atribuído aos múltiplos gêneros musicais frequentemente contemplados por eles. Por essa vertente, Penna (2006, p. 40) aborda a diversidade das manifestações musicais adotadas em trabalhos "educativos extraescolares" como um meio de "promover a troca de experiências e a ampliação do universo cultural dos alunos". Em sua fala a autora vem afirmar que:

[...] os projetos educativos extra-escolares têm mostrado uma enorme diversidade de possibilidades: em alguns, trabalha-se a música erudita; em outros, alguma das diversas expressões da música popular, como o chorinho, o rap ou as percussões de origem afro. De qualquer forma, acreditamos ser essencial tanto o diálogo com as várias manifestações culturais dos 
grupos envolvidos [...] quanto a troca com outras possibilidades de produção musical [...] (Penna, 2006, p. 40).

Através de pesquisas que abordam os trabalhos desenvolvidos em ONGs podemos observar o que Penna (2006) descreve nesse argumento. Kleber (2006) é um desses trabalhos que, por meio de práticas musicais observadas em duas ONGs, nos coloca diante de um quadro que ilustra perfeitamente a citação anterior. O Projeto Villa-Lobinhos (PVL), ligado à ONG Viva Rio, no Rio de Janeiro, é um desses exemplos. Em suas práticas de grupo, observa-se que uma das propostas desse projeto é a Orquestra Villa-Lobinhos, composta em média por 40 integrantes, todos eles alunos e ex-alunos do projeto. O repertório abarca variados estilos e gêneros da música erudita e popular (Kleber, 2006b, p. 76). Na mesma pesquisa, está em evidência outro exemplo, a Associação Meninos do Morumbi (AMM), uma ONG composta por mais de 3.500 crianças e adolescentes de São Paulo. Em seu trabalho musical, a AMM inclui a Banda Show, formada pelo Grupo de Percussão, pelo Grupo Vocal Feminino e pelo Grupo de Dança, que sintetizam as realizações das aulas de canto, dança e percussão. O repertório executado pela Banda Show em ensaios e apresentações inclui músicas do folclore brasileiro, da África, do universo pop, dos cultos afro-brasileiros, e as composições próprias (Kleber, 2006b, p. 179).

Nos dois exemplos apresentados pela autora, vê-se claramente que tanto o PVL como a AMM fazem uso da diversidade cultural em suas práticas musicais. Entretanto, considerar apenas a variedade de gêneros abordada por um determinado repertório como o único meio de uso da diversidade cultural não abrange completamente essa esfera, não permite evidenciar todas as questões que envolvem as dimensões do pluralismo cultural e não propicia atingir o seu potencial formativo-humano. Sobre essa questão, Queiroz (2015) considera ingênuo compreender a diversidade musical apenas por meio da junção de diferentes músicas em ações educativas. Para esse autor, a riqueza expressa na diversidade de formas musicais é pobre quando comparada com inúmeras dimensões da diversidade humana que permeiam as expressões musicais (Queiroz, 2015, p. 209). Contudo, retornando ao exemplo apresentado por Kleber (2006), a ONG AMM acrescenta à diversidade cultural do repertório uma ação interdisciplinar entre três expressões artísticas, o que nos permite entender nesse caso a interdisciplinaridade também como uma forma de diversificação artística e educativa.

Por esse viés, Cançado (2006), em uma discussão sobre o caminho da educação diante da diversidade humana, apresenta a interdisciplinaridade como uma das possiveis acepções do termo diversidade. A autora expõe uma reflexão sobre a experiência do Projeto Cariúnas, um trabalho sociocultural que se desenvolve com crianças e adolescentes na periferia de Belo Horizonte, que tem na interdisciplinaridade o seu objeto de referência (Cançado, 2006, p. 18). No Projeto Cariúnas, desde a primeira etapa, a integração das atividades já é trabalhada com os alunos iniciantes. Por meio de aulas integradas "os educandos participam de vivências simultâneas nas áreas de musicalização, 
do canto coral, do teatro e da dança" (Cançado, 2006, p. 20). Sendo assim, a diversidade cultural se apresenta por meio da integração de atividades. Esse aspecto favorece a prática de experimentação e uma variedade de elementos concretos à disposição do aluno (Cançado, 2006, p. 22).

Diante do que foi exposto, compreendemos que tanto a diversidade como a interdisciplinaridade, estando presentes nos amplos contextos de educação musical, estarão contribuindo com o processo de socialização de seus usuários, bem como para a realização de experiências significativas.

Na ótica de Clifford Geertz (1973), a música, sendo uma expressão cultural, faz parte das estruturas (teias) de significados das quais o homem materializa as suas experiências. Sendo assim, por intermédio da música, as dimensões humanas e representativas atuam na esfera dos significados.

Por essa perspectiva de um ensino musical significativo, Queiroz (2005, p. 50) afirma que "a música se configura com um sistema estabelecido a partir do que a própria sociedade que a realiza elege como essencial e significativo". O autor observa que os estudos na área da educação musical conduzem as reflexões em favor de um ensino de música que compreenda esse processo como representações de "sistemas culturais determinantes do que o homem percebe, pensa, gosta, ouve, sente e faz" (Queiroz, 2005, p. 50).

Ampliando as abordagens sobre a esfera dos significados, Queiroz (2015) expõe as "expressões idiossincráticas" musicais de cada cultura por meio de dois planos. O plano físico refere-se às formas de organizar ou desorganizar os sons; e o plano simbólico, o modo de conceder significado ao plano sonoro. Detalhando os dois planos, o autor apresenta a seguinte concepção:

Se o som nos permite perceber as singularidades de como cada cultura fisicamente expressa sua música, o significado nos possibilita perceber que música está vinculada à vida e, portanto, relacionada a todas as dimensões que nos singularizam como seres humanos: gênero, raça, etnia, orientação sexual, religião etc. (Queiroz, 2015, p. 210).

Compreender a diversidade cultural como um dos meios de ação pedagógica capaz de construir significados para o aprendizado musical torna-se então uma condição sine qua non para uma atuação condizente com a postura dos projetos sociais militantes. O que se observa é que o âmbito da diversidade cultural e seus significados possibilitam reflexões capazes de conduzir o educador a ir além de si mesmo, "a enxergar, ouvir, perceber, reconhecer, respeitar e interagir com o outro" (Queiroz, 2017, p. 99). Essa concepção implica o alargamento de parâmetros, valores e significados que necessitam ser estabelecidos a partir de bases "transculturais", que nos forneçam a capacidade de compreender e interagir com a cultura e a singularidade do outro (Queiroz, 2017, p. 99). Sendo assim, ir além de si mesmo representa, mais do que uma postura ética, a efetivação de ações motivadas por uma formação musical "em prol do amor a humanidade", por meio da qual o educador 
poderá seguir ampliando limites e dissolvendo preconceitos, construindo uma relação de envolvimento musical "com e para o outro" (Queiroz, 2015, p. 197).

Para as ONGs comprometidas com o desenvolvimento da autonomia e de valores éticos em seus alunos, esses caminhos diversificados do fazer musical e suas dimensões dinâmicas de abordagens educativas representam uma necessidade primordial. Essa afirmação é baseada no fato de que frequentemente os projetos sociais estão destinados a atender pessoas que se encontram em condições precárias de vida, portadoras de necessidades urgentes, com pouquíssimas alternativas de realizações. Sendo assim, torna-se também urgente compreender a diversidade do mundo social e cultural que cerca essas pessoas. Essa reestruturação conceptiva por parte da educação musical permite intervenções pedagógicas comprometidas em atender as especificidades de cada contexto. Desse modo, uma prática musical significativa para uma determinada comunidade terá a capacidade de ser envolvente, e por intermédio do envolvimento poderão ser concretizados os diversos meios educacionais que favoreçam alcançar os objetivos de um determinado projeto, bem como os amplos beneficios para a formação humana de seus integrantes.

\section{O PROCESSO METODOLÓGICO DA PESQUISA NA ONG}

\section{ILHA DE MÚSICA}

Pesquisar o trabalho de educação musical adotado pela Ilha de Música por meio da abordagem qualitativa permitiu, dentre outras esferas, buscar esclarecimentos sobre as relações humanas inseridas nesse fenômeno. Goldenberg (2004) argumenta que os fatos sociais apresentam sentido próprio e cada caso em especial deve ser compreendido em sua singularidade. Portanto, para poder identificar as ações educativas da Ilha de Música, faz-se necessária uma "compreensão interpretativa das experiências dos indivíduos dentro do contexto em que foram vivenciadas" (Goldenberg, 2004, p. 19).

A modalidade qualitativa adotada foi o estudo de caso, sobretudo pela necessidade de se realizar um mergulho holístico e profundo nas práticas educacionais da Ilha de Música. Por essa perspectiva, Laville e Dionne (1999) entendem a possibilidade do aprofundamento como a vantagem mais marcante no uso desse método e afirmam que o estudo de caso permite ao pesquisador "mostrar-se mais criativo, mais imaginativo", com mais tempo para adaptar seus instrumentos, e assim poder "modificar sua abordagem para explorar elementos imprevistos" (Laville; Dionne, 1999, p. 156).

Com a intenção de obter um melhor conhecimento histórico do contexto inerente ao terceiro setor, e assim optar por estratégias e técnicas metodológicas que se adequassem com a temática, foi realizada uma pesquisa documental. Também para buscar uma ampla compreensão das ações educativas adotadas pela Ilha de Música e como parte constitutiva do aprofundamento que essa tarefa demandou, fez-se necessário atentar não apenas aos conteúdos e ações pedagógicas dos professores da ONG, mas incluir no foco de observação qualquer relação humana possivvel de ser observada. Esse procedimento metodológico é inspirado no antropólogo e sociólogo francês Marcel Mauss. 
O autor em questão, ao estudar um poema escandinavo no qual se evidenciam diversas relações sociais em sociedades arcaicas, entende a complexidade das relações humanas como fenômenos sociais "totais" (Mauss, 2003). Fundamentado por esse mesmo autor, Kleber (2006) transfere essa interpretação para as relações humanas observadas em ONGs, compreendendo-as como um fenômeno social que envolve diferentes dimensões e contextos, portanto "um fato social total, não se reduzindo a um processo de ensino e aprendizagem musical, ainda que este considerado na sua multiplicidade" (Kleber, 2011 p. 36, grifo da autora).

Nesse sentido, através de observações nas relações interpessoais entre integrantes da Ilha de Música, buscou-se compreender os efeitos das ações educativo-musicais adotadas. Entendemos que os sujeitos da pesquisa são todos os integrantes da ONG, desde professores, alunos, pais de alunos, funcionários e coordenadores, pois, de forma direta ou indireta, todos contribuem para a compreensão do fenômeno pesquisado. No entanto, é por meio dos relatos dos entrevistados (os colaboradores diretos desta pesquisa) que foi construído de forma mais específica o conteúdo investigativo e inspirador de reflexões que, em uma relação dialética com os autores que fundamentam este estudo, impulsionaram o desenvolvimento argumentativo.

As entrevistas semiestruturadas foram realizadas com seis profissionais que trabalham na Ilha de Música. Sendo assim, colaboraram com esta pesquisa os dois fundadores do projeto, a ex-coordenadora, o diretor da ONG, dois professores e dois ex-alunos que atuam hoje como professores. As temáticas das entrevistas foram pensadas no sentido de explicar o surgimento da ONG Ilha de Música, com qual objetivo foi criada, os métodos de ensino adotados, as práticas de ensaios, as apresentações em público, o objetivo principal do trabalho educativo que lá se realiza, as possiveis mudanças percebidas ao longo do tempo no comportamento dos alunos, as dificuldades encontradas no trabalho, os objetivos alcançados ou não, e as contribuições deixadas aos ex-alunos.

Ao lançar a proposta do estudo, explicando as questões éticas que essa escolha representa no âmbito da pesquisa científica, todos os participantes foram unânimes em permitir tanto o uso de seus nomes como de suas imagens.

A construção dos dados deu-se desde as primeiras observações no cotidiano da ONG. Nesse campo de análise estão as reflexões sobre a atuação do pesquisador e também professor de musicalização infantil na ONG Ilha de Música. As relações humanas nas mais variadas vivências que o projeto possibilita foram captadas em diferentes formas de registro, como o uso de um diário de campo; fotografias; realização das entrevistas semiestruturadas; gravações (vídeo e áudio) de aulas, ensaios, recitais internos, bastidores de shows e das apresentações musicais. Esses instrumentos de coleta serviram para compor o material necessário à construção dos dados.

O desafio que esteve presente durante todo o processo no desenvolvimento deste estudo foi o de separar as funções de professor de um dos autores - que, fazendo parte da instituição, contribui com decisões tanto peda- 
gógicas como de funcionamento da ONG - da função e as necessidades do pesquisador. Tornou-se relevante exercitar um novo olhar para o fenômeno Ilha de Música, enxergar as particularidades antes não percebidas. Transformou-se em algo substancial conseguir observar o fenômeno como se fora o primeiro olhar a ele focado. Por essa ótica, Karl Kraus (2010) sugere que possamos "enxergar abismos nos lugares comuns" como uma forma de nos capacitarmos a uma prática de constante renovação do nosso entendimento sobre as coisas do mundo.

\section{Contextualizando a IlHa de Música}

A organização não governamental Ilha de Música está situada na rua Padre Cícero Romão $\mathrm{n}^{\circ}$ 560, comunidade da África, bairro da Redinha, na Zona Norte do Municipio de Natal, RN, Brasil. A Zona Norte é conhecida por possuir uma comunidade de menor poder aquisitivo da capital potiguar. $\mathrm{O}$ local em que a ONG se situa é um dos mais carentes e violentos da Zona Norte.

A ONG foi fundada em 2006 por um casal de voluntários, Inês Latorraca ${ }^{1}$ e Gilberto Cabral, ${ }^{2}$ com a intenção de colaborar com a melhora da qualidade de vida dos moradores da comunidade da África, oferecendo um trabalho educacional que utiliza a música como um meio de formação humana, de socializar crianças e jovens, de protegê-los da violência do bairro e como uma possivel alternativa de inserção profissional.

Entre os anos de 2006 e 2018, a ONG Ilha de Música atingiu em torno de 800 crianças e adolescentes. O projeto acolhe crianças a partir de 8 anos de idade. Dos 8 aos 12 anos, a criança é introduzida na musicalização infantil, podendo também ter aulas do instrumento de sua preferência. Desde sua entrada, a criança é estimulada a experimentar os instrumentos musicais. Instrumentos de percussão, flauta doce, o canto popular, violão, guitarra, baixo elétrico, bateria, piano, clarinete, saxofone, trompete e trombone são as opções oferecidas. Além das aulas de musicalização infantil, das oficinas de instrumentos, das aulas coletivas, dos ensaios, apresentações em recitais e shows fora do espaço físico da ONG, a Ilha de Música tem proporcionado às suas crianças e jovens variadas vivências, como orientações culinárias, reforço escolar em diversas disciplinas, palestras sobre higiene dental, palestras preventivas contra possiveis contaminações, e acompanhamento psicológico para pais e alunos. Outro fator relevante de ser citado no que se refere à formação e acompanhamento do desenvolvimento de seus alunos é o fato de a Ilha de Música ter criado desde o princípio uma aproximação para o diálogo e parceria com as familias dos alunos e as coordenações das escolas regulares que estes frequentam. E, sendo assim, estabelece uma triangulação entre famílias, escolas regulares e a Ilha de Música. Segundo alguns depoimentos - alguns gravados no documentário Ilha de Música, disponivel na plataforma virtual YouTube (Ilha..., 2016), outros anotados em caderno de campo

1 Idealizadora e criadora da ONG, coordenadora da Ilha de Música durante 11 anos, de 2006 a 2017.

2 Idealizador, criador, professor, diretor musical, arranjador e compositor da ONG Ilha de Música. 
durante conversas, entrevistas e reuniões na $\mathrm{ONG}-$, nas opiniões de pais, de coordenadores das escolas regulares, de professores e da própria psicóloga da ONG, o trabalho musical que vem sendo desenvolvido na Ilha de Música tem favorecido uma significativa melhora no comportamento, na atenção e no desenvolvimento cognitivo de algumas crianças.

É permitido participar da Ilha de Música qualquer criança ou adolescente que esteja matriculado na rede pública de ensino, e estes podem lá permanecer até o ano em que completam 18 anos de idade. A Ilha, como é mencionada entre os seus usuários, está a serviço da comunidade somente no período matutino, portanto atende às crianças e jovens que estudam em escola regular no período vespertino. A partir das $8 \mathrm{~h}$ recebem-se as crianças, é servido um café da manhã e às 8 h30 dá-se início às atividades de aulas ou ensaios.

Além das aulas musicalização infantil e de instrumentos, quase todas coletivas, que ocorrem nas segundas, terças e quartas-feiras de cada mês, a Ilha dispõe de três grupos musicais, que são: o grupo principal e os chamados subgrupos, compostos pelo grupo de prática de conjunto e a charanga. Os ensaios não visam apenas apresentações em recitais na própria sede ou em shows fora do espaço físico da Ilha; mais que isso, eles representam, segundo a concepção apresentada por todos os professores da ONG, o cerne da educação musical ofertada pela Ilha de Música, ou seja, a coletividade, a sociabilidade e um fazer musical prático voltado à construção de repertórios.

O grupo principal foi o primeiro a ser criado, segundo Gilberto Cabral "desde a primeira semana". Sendo assim, o grupo principal existe desde os momentos iniciais, desde o surgimento da ONG. Essa ideia de logo formar um grupo para apresentações tornou-se uma característica marcante da educação musical adotada na Ilha. Gilberto $\mathrm{Cabral}^{3}$ entende que o desenvolvimento musical deve estar intrínseco à prática de apresentar-se em público e explica essa sua escolha pedagógica por meio do seguinte argumento:

[...] a metodologia principal que eu uso é aproveitar o que eles já sabem e colocar isso musicalmente [...] eu vou aproveitar essas quatro notas que você toca e vou criar uma música em cima disso que você já está fazendo [...] Eu faço isso porque eu tinha uma crítica nos lugares que eu estudava que ensinavam tudo a gente, era um excelente músico dentro da sala, mas quando saía dali pra se apresentar era todo mundo nervoso, era sem saber tocar, não sei o quê, e tal. [...] Então pronto, a minha metodologia, eu disse olha, eu vou criar logo um grupo, rapidamente pra que eles, não vão tocar? Se vai tocar, vai se exibir, e pra se exibir tem que praticar isso desde cedo [...].

É perceptivel em sua fala uma atenção com os aspectos psicológicos que envolvem a apresentação em público. Vê-se um especial cuidado para poder

\footnotetext{
3 Entrevista concedida a José da Silva Fontes Junior, em Natal, em 16 de março de 2018.
} 
tornar a apresentação um momento importante, porém que seja compreendido com leveza e naturalidade, para que o músico possa não vir a adquirir o medo do palco. A partir dessa estratégia, o grupo logo começou a ser visto em eventos pela cidade; sendo assim, o grupo principal, além de servir como aprimoramento para o desenvolvimento musical de seus integrantes, tornou-se também uma espécie de espelho do trabalho educativo musical que a Ilha de Música exerce.

A princípio, esse grupo atuava com menos instrumentos, apenas aqueles que a Ilha dispunha no início de suas atividades. Atualmente, o grupo principal é formado por 15 integrantes e faz uso de todos os instrumentos musicais oferecidos nos cursos, os mesmos citados anteriormente.

Por atuar desde o princípio da ONG, esse grupo é o que tem dado mais representatividade ao trabalho realizado na Ilha. Assim sendo, alguns acontecimentos foram marcantes, pois possibilitaram importantes vivências para os integrantes, servindo também de incentivo para os organizadores buscarem novas alternativas para a continuidade e melhoria do trabalho que a Ilha de Música oferece.

\section{ANÁLISE DOS RESULTADOS}

O processo da compreensão das dimensões formativo-musicais exercidas pela ONG Ilha de Música permitiu enxergar o quanto as dinâmicas que geram seu funcionamento são flexíveis e mutantes. A rede de relações que a move e a mantém viva está sempre suscetivel a mudanças. A ideia de seus fundadores, de que se torne autossustentável, tem gerado constantes transformações e movimentações em seu funcionamento. Essas transformações atingem o núcleo de profissionais atuantes e movimenta um fluxo de pessoas que por algum motivo se envolvem com o projeto. As funções exercidas também são flexiveis, fato esse que tem demandado eventualmente algumas trocas de atribuições no funcionamento da ONG. Alguns alunos da primeira geração tornaram-se professores e atuam ensinando, dirigindo atividades, ensaios e apresentações. O exercício da autonomia reiteradamente transmitido no cotidiano da Ilha por seus dirigentes têm colaborado para a construção de um caráter orgânico, versátil e mutável que a Ilha de Música conquistou e dispõe no seu momento atual.

Os aspectos convergentes nas falas dos entrevistados revelou um sincronismo entre as concepções em muitos assuntos abordados e diferentes focos sobre os mesmos aspectos, sejam eles pedagógico-musicais ou não.

Sobre a motivação para criação da ONG fica claramente evidenciada nas falas dos criadores do projeto uma atenção e preocupação social com o meio no qual eles se sentem inseridos. Gilberto $\mathrm{Cabral}^{4}$ - criador, diretor musical e professor da Ilha de Música - destaca uma necessidade pessoal de retribuir o que ele mesmo teve em sua infância gratuitamente, o ensino de música.

\footnotetext{
4 Entrevista concedida a José da Silva Fontes Junior, em Natal, em 16 de março de 2018.
} 
Sua companheira Inês Latorraca ${ }^{5}$ - criadora e coordenadora por 11 anos do projeto - argumenta sobre uma "vontade de compartilhar ideias, de alguma forma colaborar com a sociedade" naquilo que ela percebe ser uma "lacuna" na comunidade onde está inserida a ONG. Ambos argumentam sobre o risco que a ociosidade do contraturno escolar representa. Em suas falas revelam que além da falta de algo construtivo que possa proteger e contribuir positivamente com suas formações, essas crianças e jovens tornam-se alvos de ações já organizadas das facções criminosas articuladas ao tráfico de drogas que atuam naquela comunidade.

A responsabilidade com o "outro", perceptivel na fala dos criadores do projeto nos remete à "responsabilidade moral" abordada por Zygmunt Bauman (1997, p. 19), que descreve as ações efetivadas para o "outro" como um ponto primordial em função de uma "legislação ética" para a sociedade.

No que diz respeito ao objetivo principal do trabalho educativo oferecido pela ONG Ilha de Música, todos os colaboradores desta pesquisa, em entrevista cedida, atribuíram a socialização como elemento essencial (Gilberto da Silva Cabral, Tarso Latorraca Casadei, Erick Rodrigues de Souza Firmino e Silvio Freire Neto Franco; ${ }^{6}$ Inês Margot Saraiva Latorraca, ${ }^{7}$ Erinaldo Edson da Silva, ${ }^{8}$ Gabriel de Oliveira Câmara ${ }^{9}$ ). Não apenas nas falas dos entrevistados, mas também nas anotações do caderno de campo foi registrado que outros profissionais que também atuam na Ilha de Música associam o verbo socializar a fatores como: dar opções às famílias da comunidade; realizar um trabalho social com música para uma educação comportamental; a música como fator agregador; a música como elemento potencial transformador de vidas. Compreendemos que em todas essas atribuições a coletividade se manifesta como elemento substancial, da mesma forma que procede de uma intenção coletiva de contribuir com o social. Por essa perspectiva, Kleber (2014) vê a música como instrumento capaz de incorporar "o senso de comunidade" e, por meio de vivências socializadas, pode vir a ultrapassar as paredes das identidades individuais (Kleber, 2014, p. 38).

$O$ poder de socialização que a música agrega evidencia-se nas pluralidades de manifestações musicais e nas diversidades de significados que suas práticas congregam em diferentes culturas. Nesse sentido, Green (1996) entende a organização social da prática musical e a construção do significado musical como aspectos fundamentais a serem apreciados na sociologia da música. Para a autora, "música é construção social” (Green, 1996, p. 29). Dialogando com essa concepção é oportuno pontuar que "o fazer musical é um tipo especial de ação social que pode ter importantes consequências para outros tipos de ação social. A música não é apenas reflexiva, mas também gerativa, tanto como sistema cultural quanto como capacidade humana"

\footnotetext{
5 Entrevista concedida a José da Silva Fontes Junior, em Natal, em 19 de março de 2018.

6 Entrevistas concedidas a José da Silva Fontes Junior, em Natal, em 16 de março de 2018.

7 Entrevista concedida a José da Silva Fontes Junior, em Natal, em 19 de março de 2018.

8 Entrevista concedida a José da Silva Fontes Junior, em Natal, em 26 de março de 2018.

- Entrevista concedida a José da Silva Fontes Junior, em Natal, em 6 de abril de 2018.
} 
(Blacking, 2007, p. 201). Nesse sentido, o compromisso com socialização expresso pelos colaboradores desta pesquisa tem alcançado resultados expressivos por uma educação musical coletiva e contextualizada com a realidade das crianças e jovens da comunidade da África.

A metodologia do ensino descrita por cada professor da Ilha de Música atende a particularidades que a cada instrumento musical correspondem. Seus discursos revelados nas entrevistas se enquadram na intenção de possibilitar um aprendizado envolvente, prático e significativo aos alunos.

Silvio Franco, ${ }^{10}$ professor de bateria e percussão da Ilha de Música, argumenta não fazer uso de uma metodologia específica; suas práticas pedagógicas são flexíveis, e estão sujeitas a possivveis mudanças que estejam de acordo com algumas necessidades observadas:

Como eu dou aula de bateria, existe um programa, né, pra eu seguir, que eu sempre segui dando aula, [...] mas ao mesmo tempo é livre, às vezes eu preciso misturar na mesma sala três que já tão há quatro anos fazendo aula e já tocam, com mais cinco que tão no primeiro ano, porque existe uma demanda daquele dia, porque um professor faltou, porque tem gente demais do lado de fora, e tá muito bagunçado às vezes, e a gente tem muita criança e tem os intervalos, aí você põe todo mundo lá dentro, aí mudou a chavinha, mudou a aula.

Na fala do professor Franco, é possivel estabelecer uma ligação com Kater (2004). O autor em questão argumenta que cabe aos profissionais da educação musical "observação e reflexão contínuas conectando criativamente e a cada instante a realidade presente objetiva" (Kater, 2004, p. 44). Entre suas colocações o autor expõe "a flexibilização do processo didático" como "prioridades a serem levadas em conta no trabalho pedagógico" (Kater, 2004, p. 47).

Continuando as abordagens sobre suas metodologias, Franco ${ }^{11}$ revela uma atenção especial com os aspectos emocionais de seus alunos, ao afirmar que

não dá pra ser aquele professor rígido [...], então levando isso em consideração, já muda muito a forma de dar aula, [...] tem esse desafio de equilibrar as turmas, ter gente na mesma turma que toque mais ou menos no mesmo nivel pra ter uma aula mais coerente, e suprir essa demanda de às vezes ter que botar todo mundo junto, né, acho que a metodologia é muito livre [...], acho que é um ensino individualizado, mesmo sendo dentro de um grupo, você tem que levar em conta a demanda do dia, e às vezes o que aconteceu na comunidade no fim de semana, pra ver se você vai pra um caminho, pra uma aula mais, sei lá, de leitura, de técnica, e tudo, porque tá todo mundo bem disposto,

\footnotetext{
10 Entrevista concedida a José da Silva Fontes Junior, em Natal, em 16 de março de 2018.
}

${ }^{11}$ Entrevista concedida a José da Silva Fontes Junior, em Natal, em 16 de março de 2018. 
ou se tá um dia meio barra-pesada e a gente tem que inventar uma coisa que alivie aquilo ali. Acho que gira muito em torno disso aí, sabe?

O "desafio de equilibrar as turmas", "a demanda do dia", a busca de uma aula que sirva como um alivio para as situações dificeis vivenciadas por essas crianças em um determinado fim de semana, essas colocações são argumentos que influenciam as escolhas dos conteúdos e das práticas musicais adotadas por esse professor. Nesse sentido, por sintonia de concepções, suas abordagens nos remetem a Fialho (2014, p. 131), que, ao discutir sobre a música na vida dos participantes de um determinado projeto social, afirma que "para atuar em projetos sociais requer inicialmente pensar em quem são seus participantes". A autora defende que nos projetos sociais o professor não deve olhar apenas para a música, interessa mais perceber como se sucede a experiência com o outro e como a música está nesse contexto. "São componentes imbricados, inseparáveis. O professor depende do aluno, que depende do professor - e a música é o elo entre ambos" (Fialho, 2014, p. 131).

O professor Firmino ${ }^{12}$ atribuiu as transformações nos alunos diretamente relacionando-as com propriedades cognitivas que a prática musical oferece. Ao ser questionado sobre o modo em que a educação musical oferecida pela Ilha de Música tem interferido na vida dos alunos, o professor deixou o seguinte parecer:

Interfere, interfere no sentido de que, de que, é música, como já assim foi dito em outras oportunidades, em outras ocasiões, o componente música dentro da vida de um indivíduo, ele vai acarretar [...] diversos traços, vamos dizer assim, que ele possa trazer pra dentro da personalidade dele, e que inclusive podem melhorar a vida dele, na questão, é sabido que música traz mais concentração, é sabido que música traz um melhor desenvolvimento cognitivo, é sabido que música vai desenvolver também questões de ordem motora, [...] ela não tem o intuito que o individuo vai se tornar um músico profissional, mas isso pode vir acontecer, como também pode não vir a acontecer, e se não vier a acontecer a música vai ter contribuído com todas essas questões que eu coloquei aí, questão da concentração, a questão cognitiva, a questão motora, a questão estética, é. Enfim, traços de personalidade, que a partir do indivíduo agregar esse conhecimento na vida dele pode fazer com que transforme, pode fazer até com que ele tenha outra visão de mundo.

Nesse sentido, o professor Erick Firmino ao expor que os beneficios provocados pelo trabalho musical desenvolvido na Ilha poderão proporcionar aos alunos uma nova visão de mundo, revela acreditar que a educação musical, "ao desenvolver programas que aumentam a competência musical, [...] estará

12 Entrevista concedida a José da Silva Fontes Junior, em Natal, em 16 de março de 2018. 
capacitando também outras habilidades do aluno, possibilitando um crescimento musical e humano integrado" (Nóbrega; Palheiros, 2015, p. 4).

Para melhor compreender as transformações oportunizadas pela educação musical oferecida pela Ilha de Música, torna-se substancial destacar essas mudanças pelas óticas dos dois ex-alunos entrevistados, Erinaldo da Silva (cursando licenciatura em música na UFRN) e Gabriel Câmara (cursando bacharelado em música na UFRN). ${ }^{13}$ No que diz respeito à formação musical realizada pela Ilha de Música, os ex-alunos contribuíram com os seguintes relatos:

A formação musical pra mim na Ilha de Música ela foi assim de um parâmetro que eu não sei nem como explicar, porque eu quando ingressei na Ilha de Música eu tinha um pensamento de estudar pra ser um engenheiro civil. Depois da Ilha de Música, o que eu posso dizer o que foi, a música [se] tornou uma profissão pra mim [...] Eu cursei o técnico, eu ingressei no técnico em 2013, né, aí depois do técnico, em 2016 eu ingressei na licenciatura e hoje eu tô no quinto período dela. Ano que vem serei, eu digo isso com orgulho, né, que eu vou ser o primeiro aluno da Ilha de Música formado em nivel superior. [...] O que eu adquiri de música antes de vir pra universidade foi tudo na Ilha de Música. Eu brinco até com Gilberto, que eu digo, o que eu sei de música eu devo ao véio da barba branca. [...] (Erinaldo Edson da Silva).

Cara, a Ilha de Música na minha inserção profissional e acadêmica, vou até prolongar para a acadêmica, foi assim, fundamental, [...] sempre os professores ficam em cima da gente pra gente ir fazer um curso técnico, uma licenciatura ou um bacharelado até um dia. E eles lá vai tipo direcionando a gente sempre pra fazer alguma coisa que você lá na frente vai colher uma coisa boa, tipo, uma licenciatura você pode dar aula, um bacharelado do mesmo jeito, um técnico, sempre eles vão incentivando a gente a crescer (Gabriel de Oliveira Câmara).

Com base no que foi observado em campo, no que foi revelado nas entrevistas e na trama dialógica que aqui se desenvolve, a ONG Ilha de Música apresenta peculiaridades que segundo a lei $\mathrm{n}^{\circ}$ 9.790/99 - que dispõe sobre a qualificação de pessoas jurídicas de direito privado, sem fins lucrativos, como organizações da sociedade civil de interesse público - lhe permite ser qualificada juridicamente como uma Oscip. Isso se dá porque por intermédio do projeto social que lá se desenvolve, os objetivos sociais promovidos estão de acordo com as seguintes finalidades expostas no art. $3^{\circ}$ : promoção da assistência social; promoção da cultura; promoção gratuita da educação; promoção da segurança alimentar e nutricional; promoção do voluntariado; promoção do desenvolvimento econômico e social e combate à pobreza; pro-

${ }^{13}$ Entrevistas concedida a José da Silva Fontes Junior, em Natal, em 26 de março de 2018. 
moção da ética, da paz, da cidadania, dos direitos humanos, da democracia e de outros valores universais (Brasil, 1999).

Diante de todo um arcabouço de informações produzidos na construção dos dados desta pesquisa, podemos identificar que a educação musical adotada pela ONG Ilha de Música, além de revelar resultados significativos no que diz respeito à formação musical e humana em seus alunos, apresenta instâncias em diferentes evidências. Por esse viés, as dimensões formativas que mais se destacaram durante a pesquisa foram a ética, a socialização, a diversidade nas práticas educativas, o oralidade nas transmissões dos conteúdos, os significados das práticas e o cuidado com o desenvolvimento da autonomia nos alunos.

\section{CONSIDERAÇÕES FINAIS}

Os resultados alcançados no desenvolvimento desta investigação revelam um ensino de música que faz uso de práticas que valorizam a intuição e a criatividade, sem abrir mão do estudo teórico musical, quando assim é necessário. Como já citado no término da seção anterior, estão presentes nas dimensões pedagógicas a ética, a socialização, a diversidade, a oralidade, os significados e a autonomia como particularidades formativas que mais se sobressaem.

A ética relaciona-se com as formas pelas quais a educação musical é proposta e desenvolvida (Bellocio, 2016), e no que diz respeito às dimensões formativas da Ilha de Música, está amalgamada em todas as outras dimensões. Os professores adotam uma postura ética por entenderem que o princípio norteador dessa educação musical é um principio ético. E, assim sendo, o ser humano tem maior importância do que os resultados musicais, ainda que esses resultados sejam de fundamental relevância para a divulgação e continuidade do trabalho.

A socialização se evidencia por intermédio do cuidado que todos os profissionais demonstram com as relações humanas. O respeito com o próximo, o cuidado com a assertividade nas relações, o sentimento de trabalho em conjunto são aspectos sempre cultivados nos discursos com os alunos e com os pais de alunos.

A diversidade está presente no repertório musical, por meio dos diversos gêneros e ritmos musicais abordados e explicados em suas origens, e também presente na transmissão musical. A interdisciplinaridade, entendida por Cançado (2006) como uma das acepções do termo diversidade, faz-se presente nas buscas por alternativas que possam disponibilizar oficinas diversas para os alunos, nas quais se desenvolvem discussões sobre diferentes esferas da vida, como: cuidados com higiene, saúde, aspectos psicológicos e comportamentais, além do contato com outras expressões artísticas.

A oralidade na transmissão musical é uma das dimensões adotadas desde o princípio da ONG e é pautada no entendimento de que a criança deve, em primeiro lugar, sentir a música, perceber os sons, manipular o instrumento 
musical e a emissão dos sons, por meio da repetição, do que ela ouve, vê, percebe e, de alguma forma, se identifica.

O cuidado em criar ambientes de práticas musicais geradores de satisfação para aqueles que os vivenciam relaciona-se diretamente com a dimensão dos significados, com o envolvimento que se efetua naquilo que significa algo efetivamente representativo em seus cotidianos. Enquanto "o som nos permite perceber as singularidades de como cada cultura fisicamente expressa sua música, o significado nos possibilita perceber que música está vinculada à vida" (Queiroz, 2015, p. 210). Tomando como base essa reflexão do autor citado, podemos buscar uma compreensão antropológica das ações educativas da Ilha. Para isso se faz necessário depositar uma observação nos significados que a música e as relações que a permeiam passam a ter na vida daquelas crianças e jovens, tanto em dias de ensaios como em dias de recitais e apresentações externas, nas quais a música é fator significativo de ligação entre essas crianças, suas famílias, a comunidade e o público que as prestigia. Por esse viés, Blacking (2007, p. 208) vem afirmar que "o fazer musical pode ser uma ferramenta indispensável para a intensificação e a transformação da consciência como um primeiro passo para transformar as formas sociais".

O compromisso com o desenvolvimento da autonomia foi identificado nas observações de campo, quando qualquer aluno ao se destacar é estimulado para dirigir trabalhos musicais em aulas, ensaios e eventuais apresentações, atuando assim como monitor em trabalhos docentes. Essas monitorias se sucederam no segundo semestre de 2018, nos cursos de trompete, trombone, percussão e bateria. As atuações dos monitores são acompanhadas e avaliadas nas reuniões da diretoria, em conversas da psicóloga da ONG com os professores, os pais dos alunos monitores e com os próprios monitores. Nessas reuniões, buscam-se alternativas para enfrentamentos das dificuldades, e são discutidas as formas de compensação pelo trabalho realizado.

No ponto de vista da contribuição social que este estudo pode abarcar, Souza (2014) afirma que sem uma análise político-pedagógica dos projetos sociais, as ações desenvolvidas podem apenas estar condicionadas em resultados atrelados a experiências assistencialistas. Nesse sentido, a discussões pedagógicas inerentes aos projetos sociais cumprem um desejo de transformação social, no qual a área de música vem se debruçando e ampliando esferas epistemológicas nas últimas décadas. O trabalho sobre a educação musical adotada na ONG Ilha de Música colabora com esses esforços, pois apresenta relevantes dimensões de uma educação musical reconhecidamente geradora de transformações sociais.

Outro fator relevante que o estudo aponta diz respeito ao fato desta pesquisa dialogar com a oralidade e apresentar possibilidade de ampliação do seu uso como forma de transmissão musical. A estratégia educacional desenvolvida e aplicada pelo professor Gilberto Cabral, ao criar composições e arranjos condizentes com os diferentes niveis técnicos de cada integrante do grupo principal da Ilha de Música, consegue estabelecer e revelar possibilidades de ações inclusivas, por meio das quais faz uso de uma estética musical envolvente, significativa, e que tem se mostrado pedagogicamente eficaz. Esse 
modelo de ensino oral e inclusivo, sendo mais aprofundado e compreendido em sua essência, poderá servir de subsídio didático e contribuir estrategicamente nos amplos contextos da educação musical.

Acreditamos que esta pesquisa possa efetivamente colaborar com a área da educação musical, somando esforços, fornecendo aportes e influenciando outras pesquisas que tenham como foco o ensino de música em projetos sociais.

\section{REFERENCIAS}

ALMEIDA, Cristiane Maria Galdino de. Diversidade e formação de professores de música. Revista da Abem, Porto Alegre, n. 24, p. 45-53, set. 2010.

ARAUJO, Anderson Henrique. Múltiplos contextos e intencionalidades do ensino de música. In: ENCONTRO REGIONAL NORDESTE DA ABET, 3.; ENCONTRO REGIONAL NORTE DA ABET, 1., 2012, Salvador. Formação e diálogos interdisciplinares na etnomusicologia brasileira. [S. l.]: [s. n.], 2012. Disponivel em: https: / / www.academia.edu/8875612/M\%C3\%BAltiplos_ contextos_e_intencionalidades_do_ensino_de_m\%C3\%BAsica. Acesso em 5 fev. 2019.

BAUMAN, Zygmunt. Ética pós-moderna. Tradução de João Rezende Costa. 2. ed. São Paulo: Paulus, 1997.

BELLOCHIO, Claudia Ribeiro. Formação de professores de música: desafios éticos e humanos para pensar possibilidades e inovações. Revista da Abem, Londrina, v. 24, n. 36, p. 8-22, jan./jun. 2016.

BLACKING, John. Música cultura e experiência. Tradução: André-Kees de Moraes Schouten. Revisão técnica: Daniela do Amaral Alfonsi, Paula Wolthers de Lorena Pires e Thaís Chang Waldman. Cadernos de Campo, São Paulo, n. 16, p. 201-218, 2007.

BRASIL. Lei $n^{\circ}$ 9.790, de 23 de março de 1999. Dispõe sobre a qualificação de pessoas jurídicas de direito privado, sem fins lucrativos, como Organizações da Sociedade Civil de Interesse Público, institui e disciplina o Termo de Parceria, e dá outras providências. Brasilia, 1999. Disponivel em: http:/ / www.planalto.gov.br/ccivil_03/LEIS/L9790.htm. Acesso em: 14 nov. 2018.

CANÇADO, Tânia Mara Lopes. Projeto Cariúnas - uma proposta de educação musical numa abordagem holística da educação. Revista da Abem, Porto Alegre, n. 14, p. 17-24, mar. 2006.

DEL BEN, Luciana. Múltiplos espaços, multidimensionalidade, conjunto de saberes: idéias para pensarmos a formação de professores de música. Revista da Abem, Porto Alegre, n. 8, p. 29-32, mar. 2003. 
FIALHO, Vania Malagutti. Ser professor de música em projetos sociais: aspectos da formação e da atuação. In: SOUZA, Jusamara; KLEBER, Magali; NASCIMENTO, Antônio Dias; FREITAS, Maria de Fátima Quintal de; WEILAND, Renate Lizana; MACIEL, Edineiram Marinho; FIALHO, Vania Malagutti. Música, educação e projetos sociais. Porto Alegre: Tomo Editorial, 2014. p. 123-136.

FREIRE, Paulo. Pedagogia da autonomia: saberes necessários à prática educativa. São Paulo: Paz e Terra, 1997.

GEERTZ, Clifford. The interpretation of culture. New York: Basic Books, 1973.

GOLDENBERG, Mirian. A arte de pesquisar: como fazer pesquisa qualitativa em ciências sociais. 8. ed. Rio de Janeiro: Record, 2004.

GREEN, Lucy. Pesquisa em Sociologia da Educação Musical. Revista Abem, Londrina, n. 4, p. 25-33, jul. 1996.

ILHA de Música. Direção: Felipe Campos. Produção: Julia Dias. Natal: Betapro, 2016. 13min51s. Disponivel em: https://www.youtube.com/ watch?v=XgpfH4EEM4M. Acesso em: 18 nov. 2018.

KATER, Carlos. O que podemos esperar da educação musical em projetos de ação social. Revista da Abem, Porto Alegre, n. 10, p. 43-51, mar. 2004.

KLEBER, Magali. A prática da educação musical em ONGs: dois estudos de caso no contexto urbano brasileiro. 2006. Tese (Doutorado em Música) Instituto de Artes, Universidade Federal do Rio Grande do sul, Porto Alegre, 2006.

A rede de sociabilidade em projetos sociais e o processo pedagógicomusical. Revista da Abem, Londrina, n. 19, p. 37-46, jul./dez. 2011.

. Música e projetos sociais. In: SOUZA, Jusamara; KLEBER, Magali; NASCIMENTO, Antônio Dias; FREITAS, Maria de Fátima Quintal de; WEILAND, Renate Lizana; MACIEL, Edineiram Marinho; FIALHO, Vania Malagutti. Música, educação e projetos sociais. Porto Alegre: Tomo Editorial, 2014. p. 27-48.

KRAUS, Karl. Aforismos. Tradução de Renato Zwick. Porto Alegre: Arquipélago, 2010.

LAVILLE, Christian; DIONNE, Jean. A construção do saber: manual de metodologia da pesquisa em ciências sociais. Tradução de Heloísa Monteiro e Francisco Settineri. Belo Horizonte: UFMG, 1999. (Biblioteca Artmed. Fundamentos da Educação). 
MAUSS, M. Sociologia e antropologia. Tradução Paulo Neves. São Paulo: Cosac \& Naify, 2003.

MORAES, Abel. Multifrenia na educação musical: diversidade de abordagens pedagógicas e possibilidades para as profissões da música. Revista da Abem, Porto Alegre, n. 13, p. 55-64, mar. 2006.

NASCIMENTO, Antônio Dias. Projetos sociais e educação. In: SOUZA, Jusamara; KLEBER, Magali; NASCIMENTO, Antônio Dias; FREITAS, Maria de Fátima Quintal de; WEILAND, Renate Lizana; MACIEL, Edineiram Marinho; FIALHO, Vania Malagutti. Música, educação e projetos sociais. Porto Alegre: Tomo Editorial, 2014. p. 51-62.

NÓBREGA, Ariana Perazzo; PALHEIROS, Graça Boal. Neojiba: reflexões sobre o ensino das práticas musicais em projeto social. In: CONGRESSO NACIONAL DA ASSOCIAÇÃO BRASILEIRA DE EDUCAÇÃO MUSICAL, 22., 2015. Natal. Anais [...]. Natal: Abem, 2015. Disponivel em: http:// abemeducacaomusical.com.br/conferencias/index.php/xxiicongresso/ xxiicongresso/paper/viewFile/1083/658. Acesso em: 5 fev. 2019.

OLIVEIRA, Alda de. Atuação profissional do educador musical: terceiro setor. Revista da Abem, Porto Alegre, n. 8, p. 93-99, mar. 2003.

PENNA, Maura. Desafios para a educação musical: ultrapassar oposições e promover o diálogo. Revista da Abem, Porto Alegre, n. 13, p. 35-43, mar. 2006.

PENNA, Maura; BARROS, Olga Renalli Nascimento de; MELLO, Marcel Ramalho de. Educação musical com função social: qualquer prática vale?. Revista da Abem, Londrina, v. 20, n. 27, p. 65-78, jan./jun. 2012.

QUEIROZ, Luis Ricardo Silva. A música como fenômeno sociocultural: perspectivas para uma educação musical abrangente. In: MARINHO, Vanildo (org.). Contexturas: o ensino das artes em diferentes espaços. João Pessoa: Ed. Universitária/UFPB, 2005. p. 49-65.

Escola, cultura, diversidade e educação musical: diálogos da contemporaneidade. InterMeio: revista do Programa de Pós-Graduação em Educação, Campo Grande, v. 19, n. 37, p. 95-124, jan./jun. 2013.

. Há diversidade (s) em música: reflexões para uma educação musical intercultural. In: SILVA, Helena Lopes da; ZILLE, José Antônio Baêta (org.). Música e educação. Barbacena: EdUEMG, 2015. (Série Diálogos com o Som, v. 2).

. Formação intercultural em música: perspectiva para uma pedagogia do conflito e a erradicação de espistemicídios musicais. InterMeio: revista do Programa de Pós-Graduação em Educação, Campo Grande, v. 23, n. 45, p. 99-124, jan./jun. 2017. 
SOUZA, Jusamara. Música em projetos sociais: a perspectiva da sociologia da educação musical. In: SOUZA, Jusamara; KLEBER, Magali; NASCIMENTO, Antônio Dias; FREITAS, Maria de Fátima Quintal de; WEILAND, Renate Lizana; MACIEL, Edineiram Marinho; FIALHO, Vania Malagutti. Música, educação e projetos sociais. Porto Alegre: Tomo Editorial, 2014. p. 11-28. 
José da Silva Fontes Junior possui graduação em Licenciatura em Música e especialização em Ensino de Música na Educação Básica pela Universidade Federal do Rio Grande do Norte (UFRN). Mestre em Educação Musical pelo Programa de Pós-Graduação em Música da Escola de Música da UFRN. Professor de baixo elétrico do Instituto de Música Waldemar de Almeida (Natal/RN). Professor de musicalização infantil da ONG Ilha de Música - Natal/RN. https://orcid.org/0000-0002-8567-9467

Valéria Lazaro de Carvalho possui graduação em Licenciatura em Música pela Universidade Federal do Rio de Janeiro (UFRJ). Mestrado em Música pelo Conservatório Brasileiro e doutorado em Educação pela Universidade Federal do Rio Grande do Norte (UFRN). Atualmente é professora associada da UFRN, atuando no Programa de Pós-Graduação em Música. Coordenadora do curso de Especialização em Ensino de Música em Múltiplos Contextos da Escola de Música da UFRN. Atua na pesquisa como vice-coordenadora do Grumus - Grupo de Estudos e Pesquisas em Música da Escola de Música da UFRN. Integrante do Banco de Avaliadores da Educação Superior - BASIs/Inep. https://orcid.org/0000-0001-5211-1122 